\title{
Study of opportunistic intestinal parasitic infections in people living with HIV and their relationship with immune status
}

\author{
Chetana G. S. ${ }^{1}$, Yadav K. ${ }^{2}$ \\ ${ }^{1}$ Dr. Chetana G S, Postgraduate in Department of Microbiology, Bangalore Medical College and Research Institute, ${ }^{2}$ Dr. \\ Kala Yadhav M L, Professor Department of Microbiology, Bangalore Medical College and Research Institute.
}

Corresponding author: Dr. Kala Yadhav M L, Professor Department of Microbiology, Bangalore Medical College and Research Institute, Email: kalayadv@redifmail.com

\begin{abstract}
Introduction: Diarrhea is one of the most common complaints people living with HIV(PLHIV), occurring in almost $90 \%$ of them. Intestinal parasites are one of the main causes of diarrhea in developing countries. Objective: The present study was under taken to detect enteric parasites in PLHIV with different levels of immune status (CD 4+ Counts). Materials and Methods: The study included a total of 209 HIV seropositive subjects. Stool samples from each subject was examined microscopically for the presence of ova and cysts using wet mount preparations and stained smears (modified ZN stain). Results: Enteric pathogens were detected in 57 (27.27\%) of the 209 patients. The parasites identified were Cryptosporidium (25), Isospora belli (3), Strongoloides larvae (2), Ascaris ova (1). In our study it was observed that the prevalence of cryptosporidium in HIV sero-positive subjects was $49.01 \%, 33.33 \%, 17.6 \%$ in those having CD4 <200, 200-499, >500 cells/ $\mu$ l respectively. Conclusion: Intestinal opportunistic parasitic infections were detected in $27.27 \%$ among HIV-seropositive patients. Cryptosporidiumis an important emerging pathogen in HIVseropositive individuals with or without symptoms.Early detection of opportunistic intestinal parasitic infections using simple techniques like wet mount and modified $\mathrm{ZN}$ staining will help in the timely management and will improve the quality of life of HIV infected individuals.
\end{abstract}

Keywords: People living with HIV (PLHIV), Diarrhea, Cryptosporidium, Isospora belli

\section{Introduction}

Opportunistic infections occur as a result of the organisms taking advantage of the weakened immune system of the host. CD-4+ T-lymphocytes are the indicators of immune status of the host. Hence opportunistic infections tend to occur more commonly in patients with decreased CD-4+ T-lymphocyte counts. HIV infection leads to decrease in immunity as it reduces the $\mathrm{CD} 4+$ cell count. Gastrointestinal infections are very common in people living with HIV(PLHIV) infection and diarrhea is a common clinical presentation of these infections[1].Bacteria, parasites, fungi and viruses are all known etiologic agents of diarrhea, although those of parasitic origin are most prominent in PLHIV in developing countries. When CD4+ counts fall below200cells/ $\mu 1$, the individual becomes susceptible to opportunistic intestinal parasitic infections caused

Manuscript received: $05^{\text {th }}$ February 2018

Reviewed: $14^{\text {th }}$ February 2018

Author Corrected: $19^{\text {th }}$ February 2018

Accepted for Publication: 24 ${ }^{\text {th }}$ February 2018 mainly byCryptosporidium parvum, Isospora belli, Microsporidium spp.,Giardia intestinalis, Entamoeba histolyticaand Strongyloidesstercoralis [2]. In PLHIV, entericparasitic infections occur with increased frequency and lead to persistent, severe, recurrent symptoms and are associated with extra-intestinal manifestations due to progressive decline in immunological responses [3].These superimposed opportunistic intestinal parasitic infections are one of the major health problems among PLHIV as they result in increased morbidity and mortality [4]. Of theopportunistic intestinal parasitic infections, Cryptosporidium parvum and Isospora belli are the two most common intestinal protozoan parasites and pose a public health problem in PLHIV. These are the only two enteric protozoan parasites that remain in the case definition of AIDS [5].Previous studies have showed that PLHIV, particularly those with a lower CD4 T cell count, have higher prevalence of opportunistic intestinal parasites. The distribution of these infections depends 


\section{Original Research Article}

on geographical location, endemicity and the living conditions of the patients $[6,7]$.Antiretroviral therapy (ART) increases the immunity of PLHIV. Utilization of chemoprophylaxis can also act on intestinal parasites, reducing their prevalence [8]. With the progressive introduction of highly active anti-retroviral therapy (HAART), modifications have been observed in the morbidity and mortality profile among PLHIV, reflected in the reduced occurrence of opportunistic infections, including those caused by intestinal parasites [9]. Studies show that the overall prevalence of intestinal parasitic infections in low CD4 cell counts is high despite the availability of ART [10]. An early and accurate diagnosis is important as many of these infections are treatable with appropriate drugs. Hencewe aimed to study the prevalence of opportunistic intestinal parasitic infections and their correlation with CD4+ cell countsas well as the association with diarrhea in PLHIV attending tertiary care hospital.

\section{Materials and Methods}

Study design: This is a hospital based cross sectional study involving HIV seropositive individuals (PLHIV)

Study period: From January 2016 to December 2016

Place of study: Bangalore Medical College and Research Institute.

Inclusion criteria: HIV seropositive individuals of age above 18 years, with or without symptoms of diarrhea
Exclusion criteria: HIV sero-negative individuals and HIV seropositive individuals of age below 18 years

Sample size: Stool samples from 209 HIV seropositive individuals of age above 18 years, with or without symptoms of diarrhea were collected.

Sample collection and processing: The clinical history of the patients such as age, sex, duration of HIV infection, presence of symptoms like diarrhea was recorded in the proforma. The samples were collected after obtaining informed consents from the patients. Sterile wide mouthed screw cap disposable containers were used to collect early morning stool samples from each subject. The processing and examination of stool specimens were carried out as per standard parasitological techniques without delay. Ova, larvae, protozoan trophozoites and cysts were detected by saline and iodine wet mount examination. Identification of the cysts of coccidian parasites like Cryptosporidium and Isospora was done by doing modified ZiehlNeelsen's Staining on dried and fixed smears [11]. The estimation of CD4+ T-lymphocyte count, peripheral venous blood of the patient was collected under strict aseptic precautions. The absolute CD4+ cell counts were done by Fluorescent Activated Cell Sorter (FACS) count system (Becton Dickenson Immunocytometry system, CA 95131-1807).

Statistical analysis: The data obtained is in the form of frequencies and projected in form oftables.

\section{Results}

A total of 209 stool samples from HIV seropositive individuals were studied, which included 138 (69.3\%) males and71 (30.6\%)females. Male to female ratio was found to be 1.94:1. The age of the subjects ranged from 18 to 68 years.

Table-1: Distribution of enteric parasites with corresponding CD4+ cell counts

\begin{tabular}{|c|c|c|c|c|c|c|}
\hline & \multicolumn{2}{|c|}{ CD4+ counts $<200$ cells $/ \mu \mathrm{l}$} & \multicolumn{2}{|c|}{$\begin{array}{l}\text { CD4+ counts200-499 } \\
\text { cells/ } \mu \mathrm{l}\end{array}$} & \multicolumn{2}{|c|}{ CD4+ counts $>500$ cells/ $\mu \mathrm{l}$} \\
\hline & $\begin{array}{l}\text { Symptomat } \\
\text { ic }\end{array}$ & $\begin{array}{l}\text { Asymptomat } \\
\text { ic }\end{array}$ & $\begin{array}{l}\text { Symptomati } \\
\mathrm{c}\end{array}$ & $\begin{array}{l}\text { Asymptomati } \\
\mathrm{c}\end{array}$ & $\begin{array}{l}\text { Symptomati } \\
\text { c }\end{array}$ & $\begin{array}{l}\text { Asymptomat } \\
\text { ic }\end{array}$ \\
\hline $\begin{array}{l}\text { Cryptosporidiu } \\
\mathrm{m} \\
\text { Oocyst }\end{array}$ & $18(8.6 \%)$ & $7(3.0 \%)$ & $11(5.2 \%)$ & $6(2.8 \%)$ & $6(2.8 \%)$ & $3(1.4 \%)$ \\
\hline $\begin{array}{l}\text { Isospora belli } \\
\text { Oocyst }\end{array}$ & $2(0.9 \%)$ & - & - & - & - & - \\
\hline $\begin{array}{l}\text { Strongoloides } \\
\text { larvae }\end{array}$ & $2(0.9 \%)$ & - & - & - & - & - \\
\hline Ascaris ova & $2(0.9 \%)$ & - & - & - & - & - \\
\hline
\end{tabular}




\section{Original Research Article}

The mean age was found to be 38.8 years. The maximum numbers ofsubjects $(32.5 \%)$ were in the age group of 31 to 40 years. The next most prevalent age group was between 41 and 50 years (22.9\%). Out of 209 HIV seropositive individuals $71(33.9 \%)$ reported symptoms of diarrhea and $138(66.1 \%)$ were asymptomatic.Enteric pathogens were detected in $57(27.2 \%)$ of the 209 samples. Out of which $36(63.2 \%)$ samples belonged to PLHIV with symptoms of diarrhea. $21(36.8 \%)$ samples were collected from asymptomatic PLHIV. Among the 57samples positive for enteric pathogens. Cryptosporidium oocyst was the commonest organism identified 51 (90\%) followed byIsospora belli-3 (5\%), Strongyloides larvae-2 (3\%), Ascaris ova-1 (2\%) asshown in figures1 to 4 respectively. The highest proportion of our study population with parasitic infection consisted of those with CD4 count less than 200 cells/ $\mu 1.25(49 \%)$ of 51 cases of Cryptosporidium cyst detected belonged to group of CD4+ cell counts <200 followed by 17 (33.3\%) in CD4+ cell counts 200-499 and $9(17.6 \%)$ in CD4+ cell counts $>500$ as shown in Table- 1 .

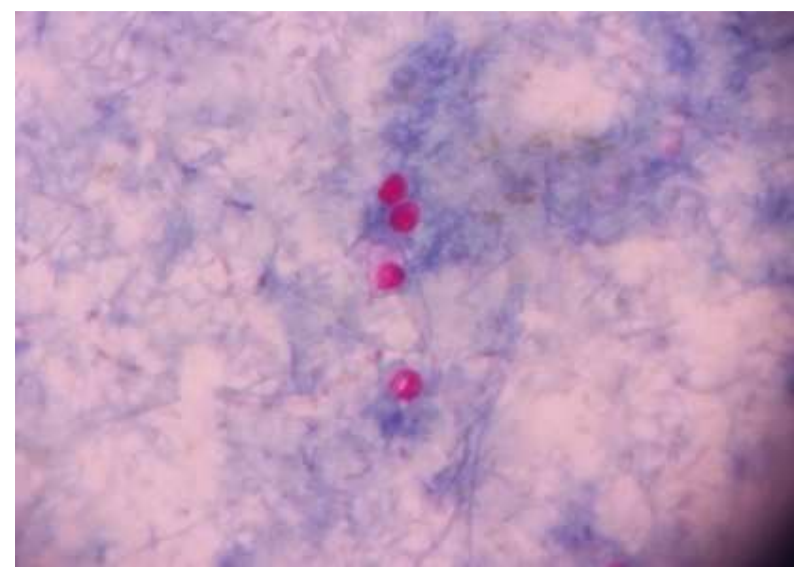

Fig-1: Cryptosporidium oocysts in modified ZN stain

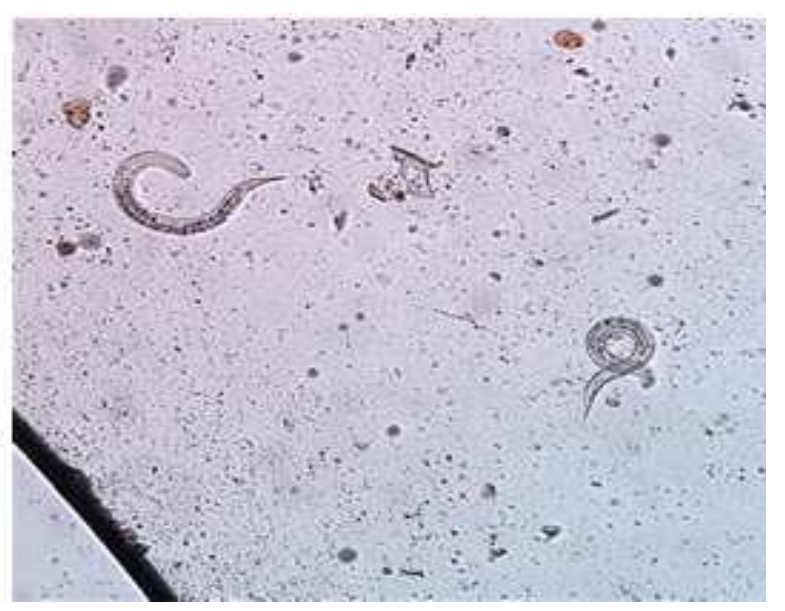

Fig-3: Strongoloides larvae in wet mount preparation

\section{Discussion}

Intestinal parasitic infections are a major public health concern in PLHIV in developing countries. Thisstudy was done to determine the prevalence pattern of intestinal parasites among PLHIV andto investigate whether the distribution of parasites was affected by immune status. As diarrhea is an important gastrointestinal symptom, acomparison conducted between the associated intestinal parasites in diarrheic and non-diarrheic patients.In our study the maximum

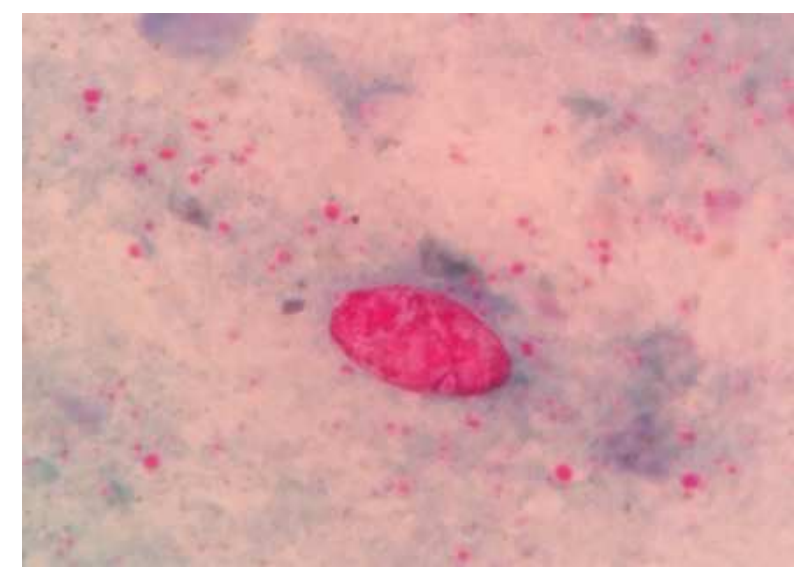

Fig-2: Isospora belli oocyst in modified ZN stain

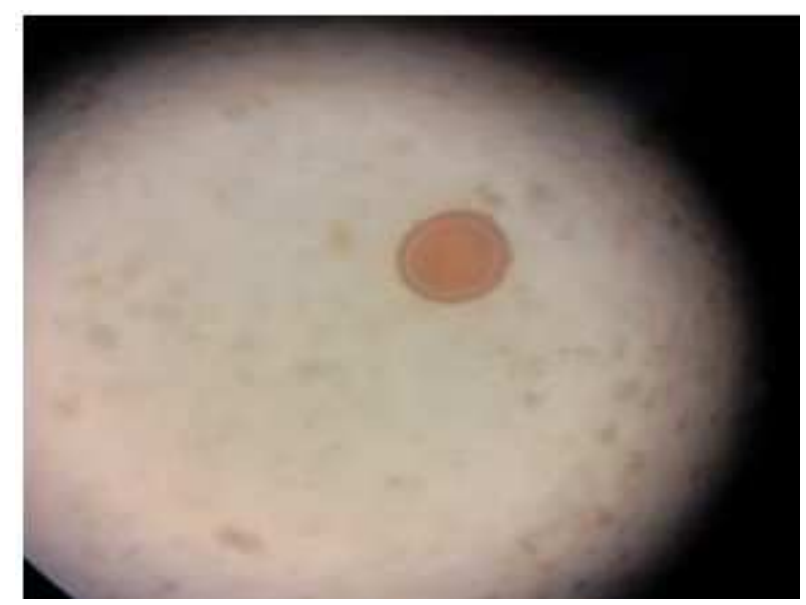

Fig-4: Ascaris lumbricoides ova in wet mount preparation numbers of patients $(32.5 \%)$ were in the age group of 31 to 40 years which is similar to the studies done by Swathirajan CR et al and Suresh VS Attili et al $[6,12]$. Where as in a study done by Nilesh S Chavan et al showed that the age distribution was common in age group of 21-30 years. In agreement with other studies, male preponderance was observed in this study which included $138(69.3 \%)$ males and 71(30.6\%)females [2, 4,6 , and 12]. Our study showed an overall prevalence of intestinal parasites among 57 (27.2\%) of the 209 


\section{Original Research Article}

study subjects. Higher rates of intestinal parasitic infections were seen in study done byNilesh S Chavan et al (58.5\%) and in a study by Rajeshwari Prabhakar $\operatorname{Rao}(49 \%)[2,3]$. Studies show variable prevalence may be due todifferent factors like environmental, parasitic and host factors.Among 57 subjects enrolled in our study, intestinal parasitic infections were detected. 36 out of the 57reported symptoms of diarrhea.This suggests that weakened immunity predisposes PLHIV to infection with opportunistic parasites which is signaled by the onset of diarrhea.

In the present study, the most predominantparasite was Cryptosporidium and was reported in 51(24.4\%) out of 209 study subjects.In the study done by Mathur MK et al showed a similar rate of infection caused by cryptosporidium [7]. The study done by Nitya vyas et al showed Cryptosporidium species was the most common enteric opportunistic parasite which accounting for $37.93 \%$ of the total parasites, followed by Isospora belli, which accounted for $31.03 \%$ [13]. Whereas the most common opportunistic parasite detected was Isospora belli $(11.5 \%)$ in the study conducted by Ahmed N H et al [14]. Among 71 symptomatic subjects, i.e., PLHIV having diarrhea, the Cryptosporidium cyst was found in 35 subjects in our study.

The prevalence of Cryptosporidium infection in HIV infected adults in different parts of the India has ranged from $0.7-87 \%$ in the symptomatic patients and from $1.4-$ $57 \%$ in asymptomatic individuals [15]. The proportion of opportunistic pathogens in patients with CD4 count $<200$ cells/ $\mu$ l was significantly higher than that in the other two groups of patients with CD4 count $>200$ cells $/ \mu 1.25$ (49\%) of 51 cases of Cryptosporidium cyst isolated belonged to group of CD4+ cell counts $<200$ followed by 17 (33.3\%) in CD4+ cell counts 200-499 and $9(17.6 \%)$ in CD4+ cell counts $>500$. Similar distribution of opportunistic pathogens in subjects with CD4 count $<200$ cells/ $/$ lwas seen in studies done by Kulkarni et al, B. Kashyap et al [1, 9].

This may be because immunodeficent patients were either more susceptible to acquire particular parasites and/or unable to clear once infection is established. This hospital based cross-sectional study provided preliminary data for further detailed information in the particular area. A study using a longitudinal design with stronger representative sample reliably investigates the possible immunologic and epidemiologic interaction between HIV infection and intestinal parasites. Thus, results of this study should be interpreted in light of the study limitations.

\section{Conclusion}

Our study detected high prevalence of intestinal parasitic infection among HIV-seropositive individuals. It also shows that Cryptosporidium is an important emerging pathogen in HIV-seropositive individuals with or without symptoms. $63.2 \%$ of all the samples in which intestinal parasitic infections were detected belonged to PLHIV with symptoms of diarrhea. This can be explained by the fact that there will be low opportunity for these parasites to proliferate and cause diarrhea as the CD4+T cell count increases.The prevalence of intestinal parasites was significantly higher in PLHIV with CD4+ T cell count $<200$ cells/ $\mu 1$. The magnitude of impairment of immunity alters the range of pathogens to which the host is susceptible. This data supports the value of standard fecalexaminations in PLHIV, since these examinations can be easily performed with low cost allowing initiation of affordable therapies. Moreover,raising immune status of PLHIV with anti-retroviral therapy may help to reduce acquisition and/or proliferation of HIV associated parasitic infections and the likelihood of experiencing diarrhea. This study emphasizes the need for routine screening of parasites especially in individuals with lower CD4 count regardless of their diarrheal status so as to ensure the early treatment can halt the progression of disease and thus improving the quality of life.

\section{Acknowledgements}

We would like to express our gratitude to the hospital laboratory staff, for their unreserved support during sample collection, processing and filling-out proformas. We also want to thank all the study participants for their willingness to participate in this study.

\section{Funding: Nil, Conflict of interest: None.} Permission of IRB: Yes

\section{References}

1. S.V. Kulkarni, R. Kairon, S.S. Sane, P.S. Padmawar, V.A. Kale, M.R. Thakar S.M. Mehendale\& A.R. Risbud. Opportunistic parasitic infections in HIV/AIDS patients presenting with diarrhoea by the level of immunesuppression. Indian J Med Res 130(1), 2009, pp 63-66. PMID:19700803.

2. Nilesh S Chavan and Swati N Chavan. Intestinal parasitic infections in HIV infected patients, 


\section{Original Research Article}

Int.J.Curr.Microbiol.App.Sci (2014) 3(2): 265-270. ISSN: 2319-7706.

3. Rajeshwari P R. Study of opportunistic intestinal parasitic infections in HIV seropositive patients at a tertiary care teaching hospital in Karnataka, India. International Journal of Contemporary Medical Research 2016;3(8):2219-2222.

4. K Gupta, M Bala, M Deb, S Muralidhar, DK Sharma, Prevalence of intestinal parasitic infections in HIVinfected individuals and their relationship with immune status, Indian Journal of Medical Microbiology, (2013) 31(2): 161-165. DOI:10.4103/0255-0857.115247.

5. Nissapatorn V, Sawangjaroen N. Parasitic infections in HIV infected individuals: Diagnostic \& therapeutic challenges. Indian J Med Res 2011; 134:878-97. Doi:10.4103/0971-5916.92633.

6. Swathirajan CR, Vignesh R, Pradeep A, Solomon SS, Solomon S, Balakrishnan P. Occurrence of enteric parasitic infections among HIV-infected individuals and its relation to $\mathrm{CD} 4 \mathrm{~T}$-cell counts with a special emphasis on coccidian parasites at a tertiary care centre in South India. Indian J Med Microbiol 2017; 35:3740.DOI:10.4103/ijmm.IJMM_16_164.

7. Mathur MK, Verma AK, Makwana GE, Sinha M. Study of opportunistic intestinal parasitic infections in human immunodeficiency virus/acquired immunodeficiency syndrome patients. J Global Infect Dis 2013;5:164-7.Doi: 10.4103/0974-777X.122012.

8. Mitra S, Mukherjee A, Khanra D, Bhowmik A, Roy $\mathrm{K}$, Talukdar A. Enteric parasitic infection among antiretroviral therapy Naïve HIV-seropositive people: Infection begets infection-experience from Eastern India. J Global Infect Dis 2016;8:82-6. doi: 10.4103/0974-777X.182124. PMCID: PMC4879795.
9. Willemot P, Klein MB (2004) Prevention of HIVassociated opportunistic infections and diseases in the age of highly active antiretroviral therapy. Expert Rev Anti Infect Ther 2:521-532.

10. Pavie J, Menotti J, Porcher R, Donay JL, Gallien S, Sarfati C, Derouin F, Molina JM. Prevalence of opportunistic intestinal parasitic infections among HIVinfected patients with low CD4 cells counts in France in the combination antiretroviral therapy era.Int $\mathrm{J}$ Infect Dis. $2012 \quad$ Sep;16(9):e677-9. doi: 10.1016/j.ijid.2012.05.1022. Epub 2012 Jul 6.

11. Garcia LS, Bruckner DA, Brewer TC, Shimizu RY.Techniques for the recovery and identification of Cryptosporidium oocysts from stool specimens.J ClinMicrobiol. 1983 Jul;18(1):185-90.

12. Attili SV, Gulati AK, Singh VP, Varma DV, Rai M, Sundar S. Diarrhea, CD4 counts and enteric infections in a hospital - based cohort of HIV-infected patients around Varanasi, India.BMC InfectDis.2006Mar1;6:39.

13. Vyas N, Sood S, Sharma B, Kumar M. The Prevalence of Intestinal Parasitic Infestation and the Related Profile of the CD4 (+) Counts in HIV/AIDS People with Diarrhoea in Jaipur City.J Clin Diagn Res. 2013 Mar;7(3):454-6. doi: 10.7860/JCDR/2013/4817.2797. Epub 2013 Mar 1.

14. Ahmed NH, Chowdhary A.Pattern of co-infection by enteric pathogenic parasites among HIV seropositive individuals in a Tertiary Care Hospital, Mumbai, India.Indian J Sex Transm Dis.2015JanJun;36(1):40-7. doi: 10.4103/0253-7184.156707

15. Ajjampur SSR, Sankaran P, Kang G. Cryptosporidium species in HIV-infected individuals in India: An overview. Nat Med J Ind. 2008; 21:178-84. PMID: 19267039.

\section{How to cite this article?}

Chetana G. S., Yadav K. Study of opportunistic intestinal parasitic infections in people living with HIV and their relationship with immune status. Int J Med Res Rev 2018;6 (02):116-120. doi:10.17511/ijmrr. 2018.i02.08. 